\title{
The sustainable development of the ethnic minorities in Vietnam: The Indian experience and policy implications
}

\author{
Thanh Hang Pham ${ }^{1, *}$ and Ekaterina Nikolaeva $^{2}$ \\ ${ }^{1}$ Institute of Religion and Belief, Ho Chi Minh National Academy of Politics, 135 Nguyen Phong Sac \\ Street, 10000, Nghia Tan Ward, Cau Giay District, Hanoi City, Vietnam \\ ${ }^{2}$ Chelyabinsk State University, 454001, 129, Br.Kashirinykh str., Chelyabinsk, Russia
}

\begin{abstract}
India is a country with diverse ethnic groups. To ensure special rights and benefits for ethnic minority groups aim at the sustainable development of the ethnic groups, the Indian Government has regulations on preferential treatment in terms of policies, capital provision, education and employment opportunities included in its Constitution. In addition to providing legal protection to minorities in the Constitution, the Government also implements national projects to promote socio-economic development in ethnic minority areas, establishing various agencies to manage issues of the groups. These are useful recommendations for Vietnam in ensuring the rights of ethnic minorities. In this article, the author will focus on clarifying the basic contents of Indian Government for ensuring the rights of ethnic minority groups and drawing some policy suggestions for Vietnam.
\end{abstract}

\section{Introduction}

India is a large country with a time-testing civilisation and the second biggest population in the world (only after China). Indian people is a mix of different races, languages and cultures. According to the 2011 census, Indian people consists of two main groups, Indo-Aryan (72\%) and Dravidian (25\%); the remaining 3\% of the population are Mongolians and other ethnic minorities (https://www.worldatlas.com). The Indian Government neither clearly classifies ethnic groups in the country, nor recognises the existence of ethnic majorities; and not clarified is the concept of ethnic minorities in the Constitution of India, either. However, from the very early stage, Article 342 of the Constitution of India uses the phrase "Scheduled Tribes" to refer to tribes, tribal groups or small, sporadic groups (http://wenku.baidu.com). Shortly, the "Scheduled Tribes" here are ethnic minorities with small quantities (about $25 \%$ of the Indian population), which are distinctive and unique in comparison to the majorities. The Indian Government relies on characteristics of language, residence, culture and population to recognise small and sporadic ethnic groups in society as well as the system of policies and laws to protect and reserve special attention for these social groups. This article analyses the guarantee of the rights of ethnic minorities in India and policy implications for Vietnam.

\footnotetext{
*Corresponding author: thanhhanghh2015@gmail.com
} 


\section{Materials and methods}

The author uses the analysis methods to collect and systemize published documents on national and international books on the ethnic policy in India. The materials and methods used in this paper is to clarify the ethnic policy of India and create a basis for proposing ethnic policy for Vietnam.

\section{Results}

\subsection{Ensuring the rights of ethnic minorities in India}

The basic contents of Indian Government for ensuring the rights of ethnic minority groups include:

Firstly, to ensure the political rights of ethnic minority areas. The Indian Government has approved laws to regulate and protect the rights of minorities. The Constitution of India specifies that tribal people (that is, people of ethnic minorities) have equal rights in politics, religion, employment, culture and education. To ensure the rights and interests of ethnic minorities, the Constitution also sets out corresponding limits for bringing non-tribal people into settlement areas of tribe and buying assets.

Article 14 in the Constitution of India states: "All are equal before the law - the State shall not deny to any person equality before law and equal protection of the laws within the territory of India" (http://wenku.baidu.com).

Article 335 of the Constitution specifies: "Scheduled Tribes" (ethnic minorities) are entitled to ask for a certain number of positions in government agencies. The rate of positions for tribes of ethnic minorities is based on the ratio of tribal people to the total population of that tribe. Moreover, the central government can directly recruit certain tribal people to hold certain positions in the central administration and reserve $7.5 \%$ of the quota for tribal people in the promotion examination. In addition to being able to serve in the Government, tribal people may also enjoy certain seats in the Parliament's House of the People and the Council of States.

It can be seen that the Constitution and laws of India always bestow ethnic minorities the right to engage in national political affairs, ensure the equality of ethnic minorities and reflect exactly the principle of national equality. The facilitation with regard to mechanisms and policies of the Indian Government in order for ethnic minorities to enjoy their political rights and interests not only creates equal space and a forum for the development of ethnic minorities, but also contribute to the effective settlement of ethnic conflicts in society and protection of the country's stability.

Secondly, to promote the economic development in ethnic minority areas. For the economic development in ethnic minority areas, the Indian Government has granted many privileges to ethnic minorities in the fields of training, employment, resource distribution and rural development promotion. Moreover, these privileges are ensured by the national legislation. Economic policies in ethnic minority areas have thus yielded many achievements.

Article 16 of the Constitution of India clearly ensures the right to employment for ethnic minorities: "No citizen shall, on grounds only of religion, race, caste, sex, descent, place of birth, residence or any of them, be ineligible for, or discriminated against in respect of, any employment or office under the State" (http://wenku.baidu.com).

However, in some ethnic minority areas of India such as the northeast, due to a large number of immigrants, the population of this area has increased rapidly, even exceeding the number of indigenous ethnic minorities. This worsens the burden of job creation and the 
allocation of development resources for Government agencies; as while causing the outbreak of large-scale campaigns of boycotting immigrants in ethnic minority areas of India.

Therefore, to address the difficulties in employment for ethnic minorities, the Indian Government has applied many specific measures such as the establishment of an agency specialised in training, fostering and testing senior positions for ethnic minorities. Third- and fourth-class civil servants of the Government are usually recruited directly by States, which can also actively determine the number of civil servants based on the ratio of ethnic minorities to their population. Since 1992, through the implementation of these measures, the Indian Government has promoted an increase in the proportion of people from ethnic minorities participating in the state civil servant system, thereby contributing to the improved employment situation of ethnic minorities.

In order to enforce rights to employment for ethnic minorities in accordance with the law, the Indian Government has also run a series of programmes to support tribes in promoting employment opportunities for ethnic minorities. The implementation of these programmes provides ethnic minorities, especially those at the low level, with not only employment opportunities and development conditions, but also a large number of vocational training facilities.

The Indian Government has launched a "Plan to fight poverty" with the primary goal of promoting employment opportunities and increasing the income for ethnic minorities, thereby helping them to escape from the poverty. Through a step-by-step subsidy measure with the principle of benefiting the poor first, the Indian Government has allocated $50 \%$ of the subsidies to support ethnic minority areas in job generation.

In addition, the Indian Government has launched two programmes to support ethnic minorities: "National Rural Employment Programme" (NREP) and "Training of Rural Youth for Self-Employment" (TRYSEM). NREP utilises the development of sustainable rural infrastructure to boost the Government's investment in rural areas and provide additional employment opportunities to farmers. As a result, the minimum food needs for the poor are ensured and the physiognomy of poor rural areas where ethnic minorities are residing has achieved considerable changes. The main beneficiaries of this programme are women and people of the scheduled tribes enshrined in the Constitution of India [2]. TRYSEM mainly provides small financial support to families living below the poverty line through commercial credits and government loans to help ethnic minorities formulate assets that can generate incomes. The Indian Government hopes that through this approach, poor ethnic minorities can rely on their abilities to form a large number of small businesses (mainly small handicrafts) in rural areas to provide employment opportunities for the poor, helping them escape from the poverty. The key method to implement this programme is to mobilise the poor to organise and form self-help groups. The programme mainly targets women, ethnic minorities and people with disabilities (50\% for ethnic minorities, $40 \%$ for women and the remaining 3\% for people with disabilities). In short, ethnic minorities are the ones who benefit the most from the programme.

The Indian Government has also issued a policy of rational exploitation of resources in ethnic minority areas. In order to improve the production capacity of ethnic minorities, the Indian Government has established a Specialised financial fund in "Five-year plans" to promote the exploitation of resources in their residential areas. The Government used Rupee 199.3 million (INR) in the "first five year plan", INR 429.2 million in the second five year plan, INR 503.3 million in the third five year plan, INR 750 million in the fourth five year plan", INR 11.12 billion in the fifth five year plan, and INR 55.35 billion the sixth five-year plan. Funding for the exploitation of resources in ethnic minority areas continuously has increased in the subsequent five-year plans.

However, in the exploitation of resources (water, forest and mines), the Indian Government has not taken the environment protection in ethnic minority areas seriously, causing water, atmosphere and soil pollution; exhausting forest resources and harming the 
interests of ethnic minorities. This has stirred the discontent among ethnic minorities and become a focal point for the concentration of ethnic conflicts in India.

In order to solve the problem of redistribution of benefits from exploiting resources in ethnic minority areas as well as harmonise and alleviate ethnic conflicts caused by the process of resource exploitation, the Indian Government has developed special protection principles for resource exploitation in ethnic minority areas. For example, ethnic minorities are entitled to autonomy in exploiting resources in their areas based on the actual conditions of these areas; no one shall impose or enforce any requirements on ethnic minorities in the name of development; development projects should meet the needs of ethnic minorities, respect their land and forest use rights, prevent the deprivation of ethnic minorities' right to control resources in the development process and actively attract foreign direct investments for ethnic minority areas to avoid exhausting the exploitation of resources in the development process [1].

The Indian Government has also focused on policies to promote rural development in ethnic minority areas, narrowing the gap between rich and poor people in society. Ethnic minorities in India make up about $25 \%$ of the Indian population and live mainly in remote rural areas with really difficult living conditions. The Indian government has implemented a wide range of support programmes to focus on the rural development in ethnic minority areas. The central government and state governments have made great efforts in the economic development of ethnic minority areas in states where the population of ethnic minorities accounts for at least half of the population of that state. A tribal area support programme (TSP) has been established. Based on the proportion of ethnic minorities in the tribal area, TSP will be approved by the state and federal governments to ensure the efficient and proper use of the TSP's fund, thereby promoting the socio-economic development in these areas. According to the proportion of people in the tribe, TSP is divided into four categories: integrated tribal development project (ITDP); modified area development approach (MADA); tribal clusters and the primitive tribal groups.

In the TSP, the most notable project is the ITDP, which is an integrated development plan for ethnic minorities. The project has been implemented since 1979 and was first started in 2,300 communities. By October 1980, the project had been developed in all rural communities. The project has mainly promoted the ability to create jobs for ethnic minorities by providing them with soft loans (by a capital subsidy rate of up to 50\%). As of November 1998, there were 53.8 million borrowers in total with a loan value of INR 195 billion. This is one of the biggest projects that the Indian Government has undertaken to help tribes of ethnic minorities. The project targets people living below the poverty line. The purpose of this project is to provide income streams and employment opportunities for poor people in ethnic minority areas.

In addition, in the rural development strategy of ethnic minority areas, it is necessary to mention the "Rural road programme" of the Indian Government. This programme, under the central government's responsibility, was started in India in late 2000. By 2008-2009, the road connecting rural areas where about 1,000 people were residing had been completed. In the northeast, mountainous areas, desert areas and areas inhabited by ethnic minorities, the roads will connect areas where more than 500 people are living. The implementation of this programme has greatly improved the living environment and production conditions of rural Indians.

Thirdly, to apply measures of educational development to ethnic minority areas. The Indian Government has strongly developed the education for ethnic minority areas through the development of relevant laws and policies. In order to improve the universalisation of education and eliminate unfair treatment towards ethnic minorities, the Constitution of India prohibits discrimination in Government-funded educational institutions. Article 46 of the Constitution of India affirms "The State shall promote with special care the educational and economic interests of the weaker sections of the people, and, in particular, of the Scheduled Tribes". 
In ethnic minority areas of India, the number of ethnic minorities receiving primary education is quite low with most students tending to drop out of school before completing the curriculum, resulting in the failure in achieving the expected rates at the elementary and higher levels.

To solve this problem, the Constitution of India states that the central government and the state governments will base on the proportion of the population of ethnic minorities to the total population to reserve a rate of $7.5 \%$ for people of ethnic minorities in educational institutions run by the central government and state governments. Moreover, the central government encourages and develops the education of ethnic minorities through laws such as ensuring the enrollment rate, lowering entry scores, setting up scholarships, offering preferential treatment, etc. The Indian Government has invested a great amount of money on education for ethnic minorities, as evidenced by the educational fund in each "five-year plan" accounting for nearly $50 \%$ of the plan's total budget.

Fourthly, to implement social security policies for ethnic minority areas. The Indian Government has approved the legal system and support projects to improve the social security level for ethnic minorities. It has not only abolished slavery in agriculture, enacted the minimum wage law to protect the rights of workers and ethnic minorities through the Constitution, but also improved the social insurance regime and protected the interests of state employees and workers in other professions through the enactment of other laws such as the Law on Insurance for State Employees, the Law on Reserve Fund and other specialised funds, the Law on Coal Mine Reserve Fund and Award Plan, Regulations on Pension Payment, the 1971 Law on Retirement, etc. These laws all provide specific provisions on benefits that State employees and workers of other professions should enjoy.

In addition to general protective provisions for ethnic minorities specified in the law, within the scope of general distribution, the Indian Government has also established a system of low-cost shops and issued purchase cards to ensure basic living needs for ethnic minorities and the poor. The low-cost shops mainly provide basic necessities for life and important household items for ethnic minorities.

For vulnerable groups in society, the Indian Government has also issued a special social security regime. For example, farmers who are old and incapable of working to meet their minimum needs of life are provided with subsidies; poor homeless farmers can receive the Government's housing subsidies to obtain basic living conditions; the education for poor children will be funded by the central government and the state government; poor ethnic minorities are beneficiaries of the cheap food policy.

To address the basic food issue for ethnic minorities in border areas and backward tribal areas, especially to eliminate the situation of children dying from hunger and malnutrition, the Indian Government has promoted the project to provide funding for the establishment of grain storage facilities, as while ensuring that every family in ethnic minority areas has $100 \mathrm{~kg}$ of grain to be stored. In addition, India's rural poverty reduction policy has provided each family in obsolete ethnic minority areas of the country with USD 150 per year.

The special above-mentioned poverty reduction projects in India have significantly reduced the prevalence of poor households in India from $44.5 \%$ in 1980 to $36.0 \%$ in 1990 , and only $26.1 \%$ in 2000 .

\subsection{Policy implications for Vietnam}

Vietnam is a country consisting of 54 ethnic groups with the characteristic languages, lifestyles and cultures of each group. Kinh groups make up more than $86 \%$ of the total population, and the next largest groups of Tay, Thai, Muong, Khmer, Nung, Mong and Dao make up about $10 \%$ of the total population. Ethnic minority groups, especially those with 
low populations, are mainly concentrated in the highlands and mountainous areas, with limited access to infrastructure, health care and education.

According to the statistics of Committee for ethnic minorities up to July 1st 2015, the total population of 53 ethnic minorities in Vietnam is about 13.4 million people (accounting for $14.6 \%$ of the national population). The midland areas and Northern mountains have the highest number of ethnic minorities (about 6.7 million people), followed by is the Central Highlands (about 2 million people), North and South Central Coast (1.9 million people), the rest mostly live in the Southern region. The amount of population of the ethnic groups is unequal. Tay, Thai, Muong, Khmer, Nung, and Mong groups have over one million people while O Du, Brau, Ro Mam, Pu Peo, Si groups La, Cong, Bo Y, Co Lao, Mang, Lo Lo groups only have from a few hundred to less than 5000 people. $89.6 \%$ of ethnic minorities live in rural areas. Hoa groups are the only ethnic minority people living mainly in urban areas (61.9\%). The table 1 below about national average population and ethnic minority population.

Table 1. Average population and ethnic minority population.

\begin{tabular}{|c|c|c|}
\hline Target & Population (people) & Ratio (\%) \\
\hline $\begin{array}{c}\text { I. Estimated average } \\
\text { population (April 1st, 2015) }\end{array}$ & $91,713,345$ & 100.0 \\
\hline Male & $45,234,104$ & 49.3 \\
\hline Female & $46,479,241$ & 50.7 \\
\hline Urban & $31,131,496$ & 33.9 \\
\hline Rural & $60,581,849$ & 66.1 \\
\hline $\begin{array}{c}\text { II. Estimated Ethnic Minority } \\
\text { Population (July 1s, 2015) }\end{array}$ & $13,386,330$ & 100.0 \\
\hline Male & $6,721,461$ & 50.2 \\
\hline Female & $6,664,869$ & 49.8 \\
\hline Urban & $1,438,315$ & 10.7 \\
\hline Rural & $11,948,015$ & 89.3 \\
\hline
\end{tabular}

Source: Committee for ethnic minorities, Overview of socio-economic situation of 53 ethnic minority groups, May 2017, https://vietnam.opendevelopmentmekong.net.

The table 2 demonstrates the percentage of ethnic minority groups who is enable to read and write at elementary level, 2015.

Table 2. Education level of ethnic minorities in Vietnam.

\begin{tabular}{|c|c|}
\hline Ethnic & Ratio (\%) \\
\hline La Hu & 34.6 \\
\hline Lu & 42.8 \\
\hline Mang & 43.8 \\
\hline Brau & 48.2 \\
\hline Mong & 48.6 \\
\hline Co Lao & 49.8 \\
\hline Ha Nhi & 50.6 \\
\hline Lo Lo & 54.5 \\
\hline Raglay & 54.9 \\
\hline La Chi & 57.0 \\
\hline La Ha & 57.5 \\
\hline Gia Rai & 59.1 \\
\hline Xtieng & 60.7 \\
\hline Kho Mu & 61.6 \\
\hline Khang & 62.4 \\
\hline Chut & 63.0 \\
\hline Bru Van Kieu & 63.3 \\
\hline
\end{tabular}




\begin{tabular}{|c|c|}
\hline Lao & 63.5 \\
\hline $\mathrm{Si} \mathrm{La}$ & 63.7 \\
\hline $\mathrm{Ba} \mathrm{Na}$ & 63.9 \\
\hline Xinh Mun & 64.0 \\
\hline Hre & 64.7 \\
\hline Cong & 67.2 \\
\hline $\mathrm{Ma}$ & 68.6 \\
\hline Dao & 70.5 \\
\hline $\mathrm{Chu} \mathrm{Ru}$ & 71.3 \\
\hline Phu La & 71.6 \\
\hline Co Ho & 72.3 \\
\hline E De & 72.4 \\
\hline Pa Then & 72.6 \\
\hline Xo Đang & 72.7 \\
\hline Bo Y & 72.7 \\
\hline Mnong & 72.9 \\
\hline $\mathrm{Co}$ & 73.0 \\
\hline $\mathrm{Ta} \mathrm{Oi}$ & 74.1 \\
\hline Ro Mam & 74.1 \\
\hline Cho Ro & 74.4 \\
\hline Khmer & 74.5 \\
\hline $\mathrm{Co} \mathrm{Tu}$ & 75.1 \\
\hline Gie Trieng & 75.7 \\
\hline $\mathrm{Pu} \mathrm{Peo}$ & 75.8 \\
\hline Giay & 76.2 \\
\hline Cham & 79.7 \\
\hline Thai & 81.3 \\
\hline Nung & 89.0 \\
\hline San Chay & 89.4 \\
\hline $\mathrm{O} \mathrm{Du}$ & 91.9 \\
\hline Hoa & 92.0 \\
\hline Ngai & 92.1 \\
\hline San Diu & 94.9 \\
\hline Tay & 95.0 \\
\hline Muong & 95.0 \\
\hline Tho & 95.0 \\
\hline
\end{tabular}

Caption of table 2: Committee for ethnic minorities, Overview of socio-economic situation of 53 ethnic minority groups, May 2017, https://vietnam.opendevelopmentmekong.net.

The country's Party and State always ensure the practice of human rights in general and the rights of ethnic minorities in particular as a measure of social development and improvement (http://www.lyluanchinhtri.vn). After consulting the experiences of India, the author of the article would like to propose some aspects as follow to ensure better the sustainable development of the ethnic minorities in Vietnam.

Firstly, to ensure an appropriate proportion of ethnic minority representatives to participate in the State's political system. The Constitution of India always sets out clear regulations to ensure the actual political rights of ethnic minorities (for example, setting a certain percentage of employment in government agencies and priorities in the exams for promotions for ethnic minority staff).

To ensure the political rights of ethnic minorities, Article 16 of the 2013 Constitution of Vietnam states "Everyone is equal before the law. No one will be discriminated in political, civil, economic, cultural or social life" (Vietnamese Constitution 2013, https://thuvienphapluat.vn). The 2015 Law on Election of Membership in National Assembly 
and People's Councils (Articles 8 and 9) of the State of Vietnam also stipulates the equal participation of ethnic minorities in the election of and running for membership in the National Assembly, People's Councils at all levels (Law on Election of National Assembly Deputies and People's Council Deputies, June 25, 2015, https://thuvienphapluat.vn), etc. Accordingly, the State also clearly specifies that the proportion of people from ethnic minorities running for the membership in the National Assembly is at least $18 \%$ total number of people on the official list. The proportion of people from ethnic minorities running for the membership in the People's Council at all levels is determined in line with the specific situation of each province.

However, in the time to come, the State needs to continue ensuring an increase in the proportion of deputies from ethnic minorities participating in the political system and State affairs through the concretisation of standards based on the specific principle of right and interest distribution, which can promote the role and responsibilities of ethnic minorities in the country's political affairs.

Secondly, to effectively implement education development projects in ethnic minority areas. The Indian Government has succeeded in addressing the education of ethnic minorities through various measures such as providing financial support, improving facilities for schools, implementing a wide range of projects on education in rural and ethnic minority areas, founding scholarships and educational incentives, enhancing the promotion of education universalisation.

Regarding the field of education for ethnic minorities, Article 61 of the 2013 Constitution of Vietnam stipulates "The State shall prioritise the educational development in mountainous and island areas and regions with extremely difficult socio-economic conditions..." (Vietnamese Constitution 2013, https://thuvienphapluat.vn). The 2018 revised Law on Education (Article 16 and 60) specifies that the State shall prioritise investments in universalising and developing education in mountainous and island areas and regions with extremely difficult socio-economic conditions.

Although, in the recent years, the State has made great efforts in developing policies as well as legislation on the education for ethnic minorities and initially achieved certain results, there are still many limitations. The lessons of India will help Vietnam to gradually improve the education in ethnic minority areas, reduce the dropout rate and improve the graduation rate of ethnic students. In addition to ensuring the proper implementation of provisions in legal documents, the Vietnamese State needs to promote the implementation of projects and establish key investment funds for education in order to achieve the short-term goal of universalising education in ethnic minority areas and the long-term goal of raising the knowledge level of ethnic minorities.

Thirdly, to promote employment policies for ethnic minorities. In Vietnam, although the State has issued many priority policies for ethnic minority areas, especially in terms of labour and employment, post-training employment still exposes limitations. The reason is that ethnic minorities mainly reside in a scattered manner with the low level of socio-economic development and quality of (physical and non-physical) human resources. Moreover, the language barrier leads to the people's limited access to information and they mainly work in agricultural and forestry sectors which are affected by natural disasters and harsh climate. The above-mentioned factors cause the shortage of jobs, especially among young people to be ever-more serious. In 2018, there were about 313,000 young people in rural areas who were jobless or lack of jobs. Many of them, including those from ethnic minorities, have to face difficulties after graduating from high schools (Many solutions to create jobs for ethnic minorities, http://danvan.vn).

To overcome the unemployment and create more job opportunities for people from ethnic minorities, Vietnam needs to implement a number of measures such as: (1) The State clearly stipulating the employment rate for ethnic minorities and particularly for the selection and 
recruitment of official servants, it is necessary to specify a reasonable percentage for ethnic minorities; (2) Establishing vocational training and fostering centres for young people from ethnic minories in mountainous areas to improve their qualifications and working skills and enhance their ability to find jobs themselves; (3) Continuing to boost the implementation of two national target programmes on sustainable poverty reduction and new-style rural development, in which special attention should be paid to vocational training and employment support for ethnic minorities; (4) Expanding the labour market and providing employment opportunities to ethnic minorities through the business networking programme. The expansion of the network connecting vocational training schools for ethnic minorities and domestic and foreign enterprises helps the majority of students (mostly at the elementary and intermediate levels) to be introduced to work in enterprises after graduating. This requestbased training model has been initially implemented successfully in some mountainous provinces in Vietnam such as Ha Giang and Dien Bien; (5) Implementing policies to support the labour export in ethnic minority areas with extremely difficult conditions. The State focuses on supporting people from ethnic minorities with initial funding sources such as training funds, travel expenses and others to create additional employment sources for ethnic minorities in foreign countries.

Fourthly, to complete social security policies in ethnic minority areas. Article 58 in the 2013 Constitution of Vietnam states "the State shall invest in the development of the protection and care of the People's health, provide health insurance for the entire people and exercise a priority policy of health care for ethnic minorities, highlanders, islanders and people living in extremely difficult socio-economic conditions" (Vietnamese Constitution 2013, https://thuvienphapluat.vn). Article 4 of the 2009 Law on Medical Examination and Treatment stipulates the State's policies on medical examination and treatment for ethnic minorities with the priority over allocating budgets to meet the people's basic medical examination and treatment needs (Law on Examination and Treatment, https://thukyluat.vn).

The State should continue to finalise policies and laws on social security to basically solve issues on the development of ethnic minorities. Policies and legislation on sustainable social security for ethnic minorities in Vietnam should first focus on investing in policies on training and developing human resources; building infrastructure (electricity, roads, schools and stations) in association with the economic development; providing free medical examination and treatment; insurance; nurturing the elderly, etc. Notably, for people of ethnic minorities who have lost their land, it is necessary to pay attention to supporting policies on residential and production lands (including short-term and long-term support plans) to ensure minimum living needs for the people. In ethnic minority areas with extremely difficult conditions, it is necessary to review policy beneficiaries and develop a set of evaluation criteria to have special support levels (in human, financial and material affairs), thereby helping people improve their lives. The supporting policies should pay attention to the mechanism of advocating private sector and mobilising all resources for poverty reduction and social security in ethnic minority areas of Vietnam.

Fifthly, to promote the socio-economic development associated with the rational exploitation of resources in ethnic minority areas. In order to achieve the goal of rapid and sustainable development in ethnic minority areas, the State needs to synchronously implement socio-economic development investment policies, pay attention to the exploitation of resources (land, water and forests) in a rational manner and the protection of environment and ensure a harmonious relationship among economic interests, social interests and national security.

In Vietnam, ethnic minority areas often have advantages in forest and land resources for developing agricultural and forestry production zones. However, because all resources are limited, we will have to pay a high cost in case of overexploitation. Therefore, in the process of exploiting advantages and strengths of ethnic minority areas, tone shall not overlook the protection, 
regeneration and development of forest and land resources in association with environmental protection. In this way, ethnic minorities can rise to enrich themselves based on the strengths of the area that they are living in, as while ensuring a sustainable life and peace of mind to live with the natural resources, protect the resources and get rich from them.

\section{Conclusion}

The appropriate resolution of ethnic issues is particularly important for the national security and social stability. India and Vietnam are both countries with diverse ethnic groups. Both the countries are faced with the issue of protecting the national sovereignty and territorial integrity and solving national issues in a rational and harmonious manner. Through the Constitution and other laws, the Indian Government has granted certain privileges to ethnic minorities to promote the development of ethnic minorities in various aspects of life. Lessons learned from India is the practical basis for Vietnam to orient the development and improvement of ethnic policies, gradually narrowing the gap, improving the quality of life and promoting inclusive development of the minorities.

\section{References}

1. Saez Lawrence, Contemporary South Asia 8 (1999)

2. Reducing Poverty in India: Options for More Effective Public Services (World Bank, Washington D.C., 1998)

3. V.D. Pham, V. Barkhatov, E3S Web of Conferences 06010, 175 (2020) doi:10.1051/e3sconf/202017506010

4. V.D. Pham, E3S Web of Conferences 03019, 157 (2020) doi:10.1051/e3sconf/202015703019

5. T.P. Tran, E3S Web of Conferences 12004, 164 doi:10.1051/e3sconf/202016412004

6. Overview of socio-economic situation of 53 ethnic minority groups (Committee for Ethnic Minorities, 2017) https://vietnam.opendevelopmentmekong.net.

7. Sudipta Paul, Tarun Kumar Das, Ramsem Pharung et al, Ecological Indicators 110, 105934 (2020)

8. E. Karlidag-Dennis, R. Hazenberg, Anh-Tuan Dinh, International Journal of Educational Development 77, 102224 (2020)

9. Ho Ngoc Son, Dong Thi Linh Chi, A. Kingsbury, Agricultural Systems 176, 102683 (2019) 